\title{
Synaptophysin and glutamate decarboxylase expression in the rat cerebellum structures in cholestasis
}

\author{
Sergey V Emelyanchik ${ }^{1}$, Olga A Karnyushko² and Sergey M Zimatkin ${ }^{2 *}$ \\ ${ }^{1}$ YaKupala Grodno State University, Belarus \\ ${ }^{2}$ Grodno State Medical University, Grodno, Belarus
}

\begin{abstract}
Aim: The aim of the paper was to estimate by immunohistochemistry the state of the rat cerebellum cortex synapses and of gamma-aminobutyric acid (GABA)ergic neurons in cholestasis. Experimental rats were anesthetizedwith ethylic ether and the common bile duct was ligated 3-5 mm below the confluence of the lobar ducts. Animals of the control group underwent sham operation. On the $2^{\text {nd }}, 5^{\text {th }}, 10^{\text {th }}, 20^{\text {th }}, 45^{\text {th }}$, and $90^{\text {th }}$ day the animals of the control and cholestasis groups were decapitated and the samples of their cerebellum cortex were prepared for immunohistochemistry to examine the synaptophysin (Syn) and glutamate decarboxylase (GAD) expression.

Results: On the $5^{\text {th }}$ day after the ligation of the common bile duct in the molecular layer of the cerebellar cortex the expression of Syn increased by $16 \%$, and on the 10 th day-by $38 \%$, as compared to the controls. In subsequent time intervals of the study it did not differ from that of the controls. On the $2^{\text {nd }}$ day after the ligation of the common bile duct the expression of GAD in the cytoplasm of Purkinje cell bodies decreased by $10 \%$. On the $5^{\text {th }}$ day of cholestasis the expression of GAD in the cytoplasm of the survived Purkinje cells increased by $28 \%$, on the $10^{\text {th }}$ day-by $41 \%$, and within 20 days it increased by $61 \%$. On the $5^{\text {th }}$ day in the baskets around PC bodies the GAD-immunoreactivity increased by $11 \%$, on the $10^{\text {th }}$ day-by $39 \%$ and on the $20^{\text {th }}$ day-by $33 \%$, as compared to the controls. However, on the $45^{\text {th }}$ and 90th day the immunohistochemical differences were not defined, as compared to the controls.
\end{abstract}

Conclusion: Cholestasis in rats induces a compensatory increase in synaptophysin and glutamate decarboxylase expression in the cerebellum cortex.

\section{Introduction}

Cholestasis is a state when the bile cannot flow from the liver to the duodenum and accumulates in the small bile ducts. Its pressure increases dramatically and bile components are passing into the blood. Bile is a complex fluid containing bile acids, cholesterol, phospholipids, bilirubin, and proteins; it is essential for the lipids digestion in the intestine. The most important biochemical markers of cholestasis are increased levels of bilirubin, cholesterol and bile salts in blood plasma, as well as an increased activity of liver enzymes-alkaline phosphatase, gamma-glutamyl transferase, and 5' nucleotidase [1,2].

In cholestasis, primarily hydrophobic bile acids and unconjugated bilirubin increasing in blood induce significant toxic effects on the brain. One of the causes of cholestasis-induced brain damage can be hypoxia due to the disturbances of blood circulation [3]. In cholestasis, the toxic bile acids disturb the permeability and structure of blood-brain barrier [4]. Unconjugated bilirubin in the brain impairs energy metabolism and induces apoptosis, cell-membrane defects, which causes enzyme leakage and hampers transport of neurotransmitters [4]. Bilirubin also interferes with DNA and protein synthesis; it interacts directly with cell membrane phospholipids and alters intracellular $\mathrm{pH}$ as well. The excess of bilirubin induces excitotoxicity via glutamate NMDA receptors and caspase-dependent pathways [5]. In addition, cholestasis induces fat malabsorption related to the decrease in bile acids in the intestine and the absorption of lipids and lipids-soluble vitamins (A, D, E, and K). Vitamin E deficiency is associated with a progressive neuromuscular syndrome that can cause cerebellar ataxia [6].

The cerebellum is not only the center of balance and coordination of movements, but also participates in the regulation of many visceral functions and higher mental processes. In our previous study we found that cholestasis damaged the neurons of the cerebellum [7], and induced in particular the loss of Purkinje cells and granule neurons $[7,8]$.Bilirubin toxicity of the cerebellar granule cells neurons is mediated by the activation of p38 MAP kinase [9], which induces a wide variety of cellular activity in response to extracellular stimuli [10]. In our previous studies we reported on the structural and metabolic disturbances in cerebellar Purkinje cells in rats with cholestasis [8]. But the data on the state of synapses and gamma-aminobutyric acid GABAergic structures in the cerebellum in cholestasis are still lacking.

The aim of the present paper was to assess the state of the rat cerebellum cortex synapses (by the detection of synaptic vesicles marker synaptophysin, Syn) and of gamma-aminobutyric acid (GABA)-ergic neurons (using GABA synthesis enzyme glutamate decarboxylase, GAD) by immunohistochemistry.

\section{Materials and methods}

\section{Animals, chemicals and experimental design}

Experiments were performed on 36 male Wistar rats weighing $200 \pm 25$ g. All experimental procedures complied with European

Correspondence to: Sergey M. Zimatkin,Head of Department of Histology, Cytology and Embryology, Grodno State Medical University 80,Gorkogo Street, Grodno, 230015, Belarus, Tel: 375152742492; Fax: 375152335341; E-mail: smzimatkin@mail.ru

Received: June 20, 2017; Accepted: July 22, 2017; Published: July 25, 2017 
Community Council Directive (86/609/EEC) for care and use of laboratory animals. This study was approved by the Biomedical Ethics Committee of the Grodno State Medical University. Rats were housed in vivarium with free access to standard laboratory food and kept under controlled environmental conditions.Experimental rats were anesthetizedwith ethylic ether and the common bile duct was ligated 3-5 mm below the confluence of the lobar ducts by applying two ligatures followed by crossection between them. Animals of the control group underwent sham operation. On the $2^{\text {nd }}, 5^{\text {th }}, 10^{\text {th }}, 20^{\text {th }}$, $45^{\text {th }}$, and $90^{\text {th }}$ day the animals of the control and cholestasis groups were decapitated, the samples of their cerebellum were collected and fixed in zinc-ethanol-formalin at $4^{\circ} \mathrm{C}$ (overnight) and then embedded in paraffin.To obtain comparable results the cerebellum samples were treated in identical conditions.

\section{Immunohistochemistry}

Paraffin $(7 \mu \mathrm{m})$ sections were cut with LeicaRM2125 (RTS microtome Germany). Immunohistochemical detection of Syn was done using a rabbit polyclonal primary antibody, Synaptophysin Antibody (PA5-27286, Thermo Scientific, USA), diluted 1:400 at $4^{\circ} \mathrm{C}$, exposure for $20 \mathrm{~h}$, in a moist chamber. Binding of primary antibodies was detected using Thermo Scientific Super Picture ${ }^{\text {max }}$ Polymer Detection Kit. Glutamate decarboxylase (GAD) was detected with mouse monoclonal primary antibodies against GAD 67, ab. 26116 (Abcam, UK), diluted 1:2000 at $4^{\circ} \mathrm{C}$, exposure for $20 \mathrm{~h}$, in a moist chamber. Binding of primary antibodies was detected using Expose Mouse and Rabbit Specific HRP/DAB Detection IHC Kit ab. 80436 (Abcam, UK).

For the standardization of the study in all samples the lateral zone of the posterior lobe of the cerebellar hemispheres was examined. The cerebellum cortex of this region bilaterally connected with sensomotor brain cortex whichallows to plan and coordinate the rapid movements of the body following one after each other. The levels of Syn and GAD expression in cerebellum cortex structures were determined. The histochemical preparations were examined, microphotographed and studied morphometrically using an Axioscop 2 plus microscope (Zeiss, Germany) with a LeicaDFC 320 digital video camera (Leica, Germany) and image analysis program ImageWarp (Bitflow, USA).

\section{Statistics}

Mean values obtained in animals of each experimental group were analyzed by nonparametric statistics (because of the small number of animals in the groups) in Statistica 10.0 for Windows (StatSoft, USA). The descriptive statistics for each parameter included determination of the median $(\mathrm{Me})$ and interquartile range (IQR). Differences between values in the control and experimental groups were regarded as significant at $\mathrm{p}<0.05$ using the Mann-Whitney U-test.

\section{Results}

In control animals, the expression of synaptophysin was detected in numerous presynaptic endings on the Purkinje cells dendrites in the molecular layer of the cerebellum, as well as in axosomatic synapses and baskets around Purkinje cells bodies. Syn expression was especially high in the granular layer glomeruli of the cerebellum (Figure 1 B, C). The intensity of synaptophysin expression in control animals did not change significantly at different time periods after sham operation (Table1).

On the $2^{\text {nd }}$ day after the ligation of the common bile duct in the molecular layer of the cerebellar cortex the expression of synaptophysin did not differ, on the $5^{\text {th }}$ day it increased by $16 \%$, and on the $10^{\text {th }}$ day-by
$38 \%$, as compared to the controls. At subsequent time intervals of the study it did not differ from that of the controls (Figure 1 B, C; Table 1).

The expression of glutamate decarboxylase (GAD67) in the Purkinje cells cytoplasm was detected (both in the bodies and dendrites) as well as in baskets around the Purkinje cell bodies. In the molecular layer GAD-immunopositive stellate and basket cells were also visible, forming numerous axosomatic and axodendritic synapses on Purkinje cells (Figure $2 \mathrm{~A}, \mathrm{C}$ ). In the granular layer GADimmunopositive neurons as well as terminals on the periphery of the cerebellar glomeruli were detected (Figure2 A, B).

On the $2^{\text {nd }}$ day after the ligation of the common bile duct in the cytoplasm of Purkinje cell bodies the expression of GAD decreased by $10 \%$ (Table 2 ). On the $5^{\text {th }}$ day of cholestasis the expression of GAD in the cytoplasm of the remaining Purkinje cells increased by $28 \%$. The baskets around perikaryon became more visible, extended, elongated in the direction of the granular layer, and showed darker staining due to the increase in GAD-immunoreactivity by $11 \%$. On the $10^{\text {th }}$ day of cholestasis the expression of GAD in the cytoplasm of the survived Purkinje cells increased by $41 \%$ and in their baskets on $39 \%$, respectively, as compared to the controls (Figure 2 B, Table 2). Cholestasis within 20 days led to the increase in the expression of GAD in the cytoplasm of the survived Purkinje cells by $61 \%$ and to the increase in their baskets by $33 \%$, as compared to the controls (Figure $2 \mathrm{D}$, Table 2). However, on the $45^{\text {th }}$ and $90^{\text {th }}$ day after the ligation of the common bile duct the immunohistochemical differences were not defined, ascompared to the controls (Table 2).
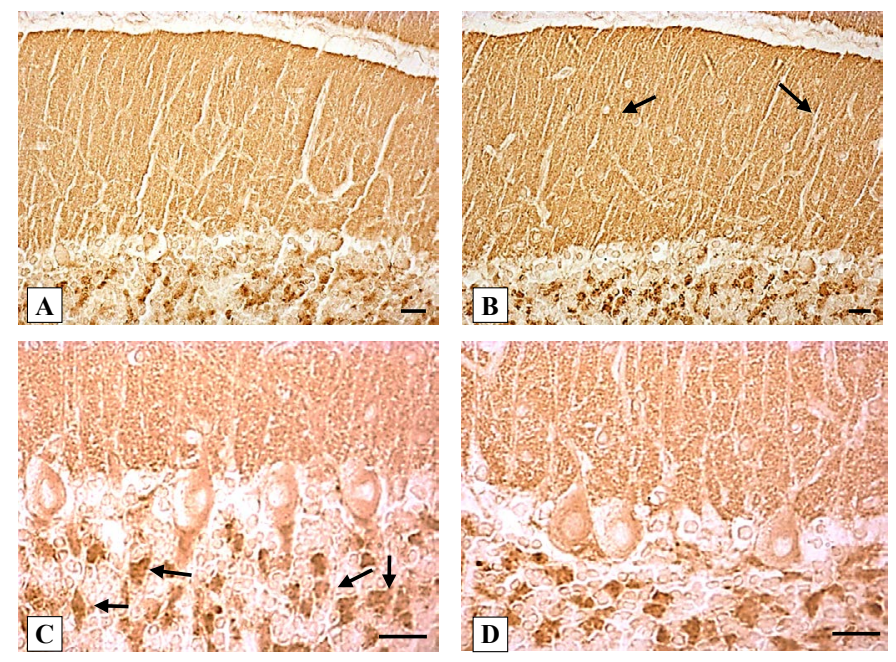

Figure 1. Expression of synaptophysin in the cerebellum cortex of rats. A, C-controls (10 days after sham operations); B, D-10 days of cholestasis. B-in the molecular layer (shown by arrows) an increase of synaptophysin expression; C-arrows show granular layer glomeruli. Digital microphotography. Scale bars-20 $\mu \mathrm{m}$. Magnifications: A, B-x200; C, D-x400.

Table 1. Expression of synaptophysin in the molecular layer of the cerebellum cortex of rats (unit of optical density $\times 10^{3}$ ).

\begin{tabular}{|c|c|c|}
\hline Days & Controls & Ligation of bile duct \\
\hline 2 & $187.03 \pm 7.5$ & $182.27 \pm 12.7$ \\
\hline 5 & $182.77 \pm 19.0$ & $211.47 \pm 5.62 * * *$ \\
\hline 10 & $189.43 \pm 15.4$ & $261.18 \pm 19.9 * * *$ \\
\hline 20 & $187.54 \pm 19.1$ & $188.74 \pm 17.6$ \\
\hline 45 & $186.77 \pm 27.2$ & $184.46 \pm 5.6$ \\
\hline 90 & $180.0 \pm 12.3$ & $182.07 \pm 14.0$ \\
\hline
\end{tabular}

Each data points are median \pm interquartile range, $\mathrm{n}=3 ; * * *-\mathrm{p}<0.001$, as compared to the controls. 

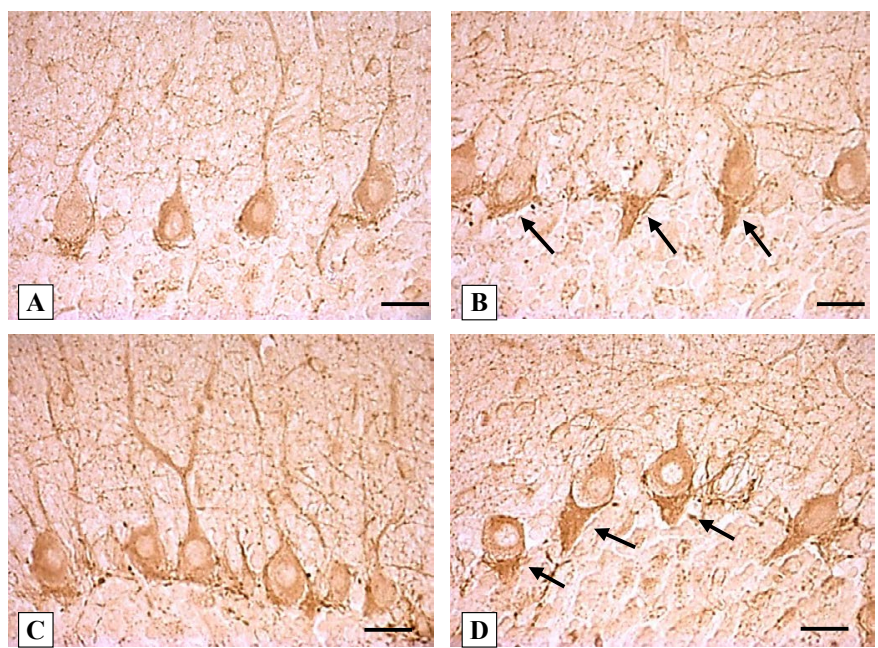

Figure 2. Expression of GAD67 in the cerebellum cortex of rats. A, C-controls (10 days and 20 days after sham operations, respectively). B-10 days, D-20 days of cholestasis. B, D-arrows show enlarged baskets with increased immunoreactivity around Purkinje cells bodies. Digital microphotography. Scale bars-20 $\mu \mathrm{m}$ Magnification $\mathrm{x} 400$.

Table 2. Expression of glutamate decarboxylase in the cerebellum cortex of rats (unit of optical density $\times 10^{3}$ ).

\begin{tabular}{|c|c|c|c|c|}
\hline \multirow{2}{*}{ Days } & \multicolumn{2}{|c|}{ Purkinje cells bodies } & \multicolumn{2}{c|}{ Purkinje cells baskets } \\
\cline { 2 - 5 } & Controls & Ligation of bile duct & Controls & Ligation of bile duct \\
\hline 2 & $182.12 \pm 2.48$ & $163.81 \pm 4.85 * *$ & $197.27 \pm 11.0$ & $188.02 \pm 14.42$ \\
\hline 5 & $160.54 \pm 2.85$ & $205.11 \pm 5.37 * * *$ & $189.73 \pm 16.09$ & $211.18 \pm 8.75 * * *$ \\
\hline 10 & $166.37 \pm 3.92$ & $235.04 \pm 4.27 * * *$ & $189.72 \pm 12.88$ & $264.26 \pm 18,64 * * *$ \\
\hline 20 & $155.51 \pm 3.86$ & $250.26 \pm 3.88 * * *$ & $189.27 \pm 10.12$ & $251.16 \pm 17.40 * * *$ \\
\hline 45 & $166.37 \pm 3.79$ & $168.13 \pm 4.44$ & $188.22 \pm 8.70$ & $190.02 \pm 14.29$ \\
\hline 90 & $166.36 \pm 3.05$ & $165.43 \pm 4.13$ & $189.73 \pm 11.27$ & $184.44 \pm 16.81$ \\
\hline
\end{tabular}

Each data points are median \pm interquartile range, $\mathrm{n}=3 ; * * \mathrm{p}<0.01, * * *-\mathrm{p}<0.001$, as compared to the controls.

\section{Discussion}

In the present study, the ligation of the common bile duct in rats induces a temporary increase (on the $5^{\text {th }}$ and $10^{\text {th }}$ day) in the expression of synaptophysin in the cerebellum cortexmolecular layer. The majority of synapses are formed by terminals of the granular cell axons (parallel fibers) on the Purkinje cell dendrites. Syn, an integral membrane protein of synaptic vesicles, is found in all nerve terminals and is involved in the synaptic transmission [11,12] playing an important regulatory part in synapse formation [13]. The temporary increase in synaptophysin in the cerebellum molecular layer can reflect the increased synaptogenesis, the number of synaptic vesicles in synapses and is a compensatory reaction. Cholestasis which induced the death of granular and Purkinje cells [8], structural and metabolic disturbances in cerebellar Purkinje cells appeared on the $5^{\text {th }}$ day after the ligation of bile duct. It reached a maximum on the $10-20^{\text {th }}$ days and decreased on the $45-90^{\text {th }}$ days. In our present study on the $20-90^{\text {th }}$ days after the ligation of the bile duct the expression of synaptophysin in the molecular layer of the cerebellar cortex did not differ from that of the controls. The recovery can be explained by the growing of new collateral bile ducts.

The increase in the expression of GAD in survived GABAergic Purkinje cells on the 5-20 $0^{\text {th }}$ days of cholestasis indicates their activation. The increase in the expression of GAD in baskets around their bodies indicates activation of GABA-ergic basket cells which can compensatory inhibits hyperexiting Purkinje cells, probably for support the functions of cerebellum.
In conclusion, cholestasis in rats induces an increase in synaptophysin and glutamate decarboxylase expression in the cerebellum cortex necessary for support the functions of cerebellum.

\section{Acknowledgements}

The authors are grateful to the English translator YaninaRazvodovskaya for the correction of the manuscript.

\section{Funding}

Grodno State Medical University grant for reagents and animals.

\section{Conflict of interest statement}

None declared.

\section{References}

1. Sotil EU, Jensen DM (2004) Serum enzymes associated with cholestasis. Clin Liver Dis 8: 41-54 vi.[Crossref]

2. Zajic S, Damnjanovic Z, Stojanovic M, Visnjic M, Dencic S, et al. (2008) Biochemical markers in patients with extrahepatic cholestasis. Acta Med Median 47: 1-12.

3. Green J, Beyar R, Bomzon L, Finberg JP, Better OS (1984) Jaundice, the circulation, and the kidney. Nephron 37: 145-152.[Crossref]

4. Greenwood J, Adu J, Davey AJ, Abbott NJ, Bradbury MW (1991) The effect of bile salts on the permeability and ultrastructure of the perfused, energy-depleted, rat bloodbrain barrier. J Cereb Blood Flow Metab 11: 644-654. [Crossref]

5. Ostrow JD, Pascolo L, Shapiro SM, Tiribelli C (2003) New concepts in bilirubin encephalopathy. Eur J Clin Invest 33: 988-997. [Crossref]

6. Grojean S, Koziel V, Vert P, Daval JL (2000) Bilirubin induces apoptosis via activation of NMDA receptors in developing rat brain neurons. Exp Neurol 166: 334-341.

7. Francavilla R, Miniello VL, Brunetti L, Lionetti ME, Armenio L (2003) Hepatitis and cholestasis in infancy: clinical and nutritional aspects. Acta Paediatr Suppl 91: 101104.[Crossref]

8. Emelyanchik SV, Zimatkin SM (2014) Structural and histochemical changes in Purkinje cells in the rat cerebellum in cholestasis. Neurosci Behav Physiol 44: 467-471.

9. Lin SZ, Yan C, Wei X, Paul SM, Du YS (2003) p38 MAP kinase mediates bilirubininduced neuronal death of cultured rat cerebellar granule neurons. Neurosci Lett 353: 209-212.

10. Zarubin T, Han J (2005) Activation and signaling of the p38 MAP kinase pathway. Cell Res 15: 11-18.[Crossref]

11. Leclerc N, Beesley PW, Brown I, Colonnier M, Gurd JW, et al. (1989) Synaptophysin expression during synaptogenesis in the rat cerebellar cortex. J Comp Neurol 280: 197212.[Crossref]

12. Greengard P, Valtorta F, Czernik AJ, Benfenati F (1993) Synaptic vesicle phosphoproteins and regulation of synaptic function. Science 259: 780-785.[Crossref]

13. Sudhof TC, Lottspeich F, Greengard P, Mehl E, Jahn R (1987) A synaptic vesicle protein with a novel cytoplasmic domain and four transmembrane regions. Science 238: 1142-1144. [Crossref]

Copyright: (C2017 Emelyanchik SV. This is an open-access article distributed under the terms of the Creative Commons Attribution License, which permits unrestricted use, distribution, and reproduction in any medium, provided the original author and source are credited. 